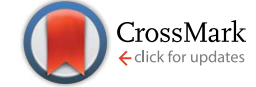

Cite this: RSC Adv., 2017, 7, 6345

Received 17th November 2016 Accepted 25th December 2016

DOI: 10.1039/c6ra26949d

www.rsc.org/advances

\section{Quasi-reverse-emulsion-templated approach for a facile and sustainable environmental remediation for cadmium}

\begin{abstract}
Ruhua Zha, ${ }^{\mathrm{a}}$ Tuo Shi, ${ }^{\mathrm{b}}$ Zongwen Zhang, ${ }^{\mathrm{a}}$ Dongli Xu, ${ }^{\mathrm{a}}$ Tongwu Jiang ${ }^{\mathrm{a}}$ and Min Zhang ${ }^{\star c}$
Nanostructured hierarchical hollow $\alpha-\mathrm{Fe}_{2} \mathrm{O}_{3}$ chestnut buds and nests were fabricated by a solvothermal process at a relatively low reaction temperature using water/glycerol and water/2-propanol as the reaction solvents, respectively. This facile and green quasi-reverse-emulsion soft-templating approach can effectively tailor the monodispersity and nanostructure of the products. The BET surface areas of the chestnut buds and nests were 424.3 and $169.9 \mathrm{~m}^{2} \mathrm{~g}^{-1}$, respectively. The maximum monolayer adsorption capacities for $\mathrm{Cd}(\Perp)$ of the chestnut buds and nests were found to be 175.8 and $126.3 \mathrm{mg} \mathrm{g}^{-1}$, respectively. Both chestnut buds and nests could be recycled with high desorption efficiency and without any remarkable loss of adsorption capacity. Owing to the surface hydroxyl groups, which were determined by FT-IR and TG-MS measurements, and the well-defined hollow mesoporous structure (pore sizes of 5.04 and $6.85 \mathrm{~nm}$, respectively), both hierarchical $\alpha-\mathrm{Fe}_{2} \mathrm{O}_{3}$ nanostructures exhibited superior prospects for the removal of $\mathrm{Cd}(\Perp)$ from wastewater in industrial practice.
\end{abstract}

\section{Introduction}

Issues of heavy metal pollution linked to wastewater have resulted in serious public concern, with the ever-growing levels of population density and industrialization. ${ }^{\mathbf{1} 2}$ Heavy metals, which are derived from battery manufacture, demilitarization of munitions, mineral exploitation, chemical fertilizers, pesticides, dye industries, pulping and paper-making, etc., are extremely poisonous water pollutants. ${ }^{3,4}$ They can lead to serious public health problems to all creatures and human beings as a result of their continual circulation via storage, accumulation and transfer through organisms. The advent of nanotechnology has created considerable opportunities to construct nanostructures with large specific surface areas, multiple valence states, variable electronic structures and related high reactivities, which can provide excellent affinity and removal efficiency for heavy metal ions. ${ }^{5-7}$ In recent years, various nanostructured iron oxides with homogeneous sizes and well-defined morphologies have received increasing attention for the decontamination of toxic heavy metal ions in contaminated water, in virtue of the advantageous properties of natural abundance, low cost, environment-friendliness and

${ }^{a}$ College of Chemistry and Chemical Engineering, Xinyang Normal University, Xinyang 464000, P. R. China

${ }^{b}$ Laboratory of Solid State Ionics, School of Materials Science and Engineering, Huazhong University of Science and Technology, Wuhan 430074, P. R. China

${ }^{c}$ Henan Collaborative Innovation Center for Energy-Saving Building Materials, Xinyang Normal University, Xinyang 464000, P. R. China. E-mail: zm201177055@ sina.com; Fax: +86-376-6370639; Tel: +86-376-6370639 large-scale availability of these outstanding adsorbents. ${ }^{8-10}$ Specially shaped metal oxides exerted strong effects in the uptake of trace metals. Therefore, the fabrication of nanostructured iron oxides with enhanced adsorption performance for the targeting of heavy metal ions has actively been pursued..$^{11,12}$ In our previously reported work, we prepared nanostructured $\mathrm{TiO}_{2}$ with the shapes of dandelions and spherical flowers via a solvothermal method. The dandelions and spherical flowers exhibited excellent adsorption capacities for Cd(II) in aqueous solution (396 and $282 \mathrm{mg} \mathrm{g}^{-1}$, respectively). Both nanostructured $\mathrm{TiO}_{2}$ particles could be repeatedly used without any remarkable loss of adsorption capacity. ${ }^{\mathbf{1 3}}$ In particular, hierarchical hollow structures with permeable backbones and large specific surface areas have emerged as fascinating material systems for rapid, efficient and economic environmental remediation. ${ }^{\mathbf{1 4 - 1 9}}$

Hematite $\left(\alpha-\mathrm{Fe}_{2} \mathrm{O}_{3}\right)$, which is a typical n-type semiconductor with an indirect band gap of $2.1 \mathrm{eV}$, possesses the most thermodynamically stable phase among all iron oxide crystal structures. ${ }^{20,21}$ In addition, it is chemically inert and environmentally friendly. Nanoscaled $\alpha-\mathrm{Fe}_{2} \mathrm{O}_{3}$, in particular hollow $\alpha$ $\mathrm{Fe}_{2} \mathrm{O}_{3}$ nanoarchitectures, have recently been proved to be admirable candidates for the disposal of various inorganic/ organic pollutants in contaminated water and air. ${ }^{2-25}$ The primary technologies used for the synthesis of hollow $\alpha-\mathrm{Fe}_{2} \mathrm{O}_{3}$ include sol-gel methods, ${ }^{26,27}$ template synthesis, ${ }^{28}$ sonochemical synthesis ${ }^{29}$ and solvothermal processes, ${ }^{18,30,31}$ etc. Three main strategies are employed in the fabrication of hollow $\alpha$ $\mathrm{Fe}_{2} \mathrm{O}_{3}$ nanostructures, namely, oriented attachment, in situ combustion of templates or precursors and self-assembly. 
Despite the fact that these synthesis technologies and strategies have many advantageous properties, there are still some deficiencies in the synthesis of hierarchical hollow $\alpha-\mathrm{Fe}_{2} \mathrm{O}_{3}$ nanomaterials. First of all, these synthesis methods typically involve the use of toxic templates. Secondly, a high temperature $(>200$ ${ }^{\circ} \mathrm{C}$ ) is needed for the decomposition of the precursor via calcination. Moreover, the majority of hollow $\alpha-\mathrm{Fe}_{2} \mathrm{O}_{3}$ nanoparticles have been prepared at elevated temperatures $\left(>180{ }^{\circ} \mathrm{C}\right)$ by hydro/solvothermal processing over a long reaction time. These requirements lead to high energy consumption and impede the large-scale industrialization of the products for practical application in water treatment. Thus, it is urgently necessary to be capable of fabricating well-crystallized hierarchical hollow $\alpha$ $\mathrm{Fe}_{2} \mathrm{O}_{3}$ nanostructures in a facile, cost-effective and green way.

In this work, two kinds of nanostructured $\alpha-\mathrm{Fe}_{2} \mathrm{O}_{3}$ hierarchical hollow spheres, namely, chestnut buds and nests, were synthesized by a facile solvothermal quasi-reverse-emulsiontemplated solvothermal process at a relatively low reaction temperature, in which moderate solvent systems of water/2propanol and water/glycerol mixtures were respectively employed to enable morphological tuning. The success of this approach was due to the presence of microheterogeneities in the water/alcohol soft template. The well-defined porous hollow $\alpha-\mathrm{Fe}_{2} \mathrm{O}_{3}$ architectures that were produced exhibited a large specific surface area and a narrow pore size distribution. It is worth noting that the surface of the nanostructured $\alpha-\mathrm{Fe}_{2} \mathrm{O}_{3}$ particles, in particular the chestnut buds, contains a large number of $\mathrm{OH}$ groups, which can act as effective active adsorption sites for chelating with heavy metal ions. Batch experiments on the adsorption of $\mathrm{Cd}(\mathrm{II})$ indicated that both adsorbents possessed superior adsorption capacities for $\mathrm{Cd}(\mathrm{II})$ and reusability in the remediation of wastewater.

\section{Experimental}

\subsection{Preparation of $\alpha-\mathrm{Fe}_{2} \mathrm{O}_{3}$ nanoparticles}

2.1.1. Nests. Nano- $\alpha-\mathrm{Fe}_{2} \mathrm{O}_{3}$ nests were prepared according to the previous study of the Nanyang Technological University research group with a few modifications. ${ }^{19}$ Typically, $50 \mathrm{~mL}$ glycerol was added to $175 \mathrm{~mL}$ deionized water at room temperature to form an alcohol-water mixture. The solvent mixture was magnetically stirred for $5 \mathrm{~min}$. Then, $0.60 \mathrm{~g}$ $\mathrm{FeSO}_{4} \cdot 7 \mathrm{H}_{2} \mathrm{O}$ (Alfa Aesar, A.R.) and $1 \mathrm{~g} \mathrm{CO}\left(\mathrm{NH}_{2}\right)_{2}$ (Alfa Aesar, A.R.) were dissolved in this solvent mixture and magnetically stirred for $15 \mathrm{~min}$. The transparent solution that was obtained was quickly transferred into a $500 \mathrm{~mL}$ autoclave and solvothermally reacted at $120{ }^{\circ} \mathrm{C}$ for $15 \mathrm{~h}$ in an electrothermal blowing dry box. After the reaction, the autoclave was cooled naturally to room temperature. The red opaque solution was centrifuged for $10 \mathrm{~min}$ and washed repeatedly with deionized water and ethanol. Finally, the red precipitate was collected and dried at $60{ }^{\circ} \mathrm{C}$ for $24 \mathrm{~h}$ under vacuum.

2.1.2. Chestnut buds. Nano- $\alpha-\mathrm{Fe}_{2} \mathrm{O}_{3}$ chestnut buds were prepared according to the previous literature with a few modifications. ${ }^{19}$ In a typical experiment, $50 \mathrm{~mL}$ 2-propanol was added to $175 \mathrm{~mL}$ deionized water at room temperature to form an alcohol-water mixture. The solvent mixture was magnetically stirred for $5 \mathrm{~min}$. Then, $0.60 \mathrm{~g} \mathrm{FeSO}_{4} \cdot 7 \mathrm{H}_{2} \mathrm{O}$ (Alfa Aesar, A.R.) and $1 \mathrm{~g} \mathrm{CO}\left(\mathrm{NH}_{2}\right)_{2}$ (Alfa Aesar, A.R.) were dissolved in this solvent mixture and magnetically stirred for $15 \mathrm{~min}$. The transparent solution that was obtained was quickly transferred into a $500 \mathrm{~mL}$ autoclave and solvothermally reacted at $150{ }^{\circ} \mathrm{C}$ for $20 \mathrm{~h}$ in an electrothermal blowing dry box. After the reaction, the autoclave was cooled naturally to room temperature. The red opaque solution was centrifuged for $10 \mathrm{~min}$ and washed repeatedly with deionized water and ethanol. Finally, the red precipitate was collected and dried at $60{ }^{\circ} \mathrm{C}$ for $24 \mathrm{~h}$ under vacuum.

\subsection{Characterization of chestnut buds and nests}

XRD patterns were obtained to study the crystal phases of the as-prepared chestnut buds and nests using a Philips diffractometer ( $\mathrm{PW} 3050,40 \mathrm{kV}, \mathrm{Cu} \mathrm{K} \alpha, 2 \theta=20^{\circ}$ to $80^{\circ}$ ). XPS measurements of the chestnut buds and nests were made using a VG Multilab 2000 system with a monochromatic Al K $\alpha$ X-ray source (ThermoVG Scientific). The structure and morphology of the chestnut buds and nests were studied by SEM (Hitachi S4800) and TEM (JEOL 2100F) experiments, in which the accelerating voltage was $200 \mathrm{kV}$. The elemental composition of the chestnut buds and nests after the adsorption of $\mathrm{Cd}(\mathrm{II})$ was determined using an energy-dispersive X-ray spectrometer (EDX) attached to a Hitachi S-4800 SEM. $\mathrm{N}_{2}$ adsorption and desorption isotherms of the as-synthesized chestnut buds and nests were recorded by physisorption of $\mathrm{N}_{2}\left(-196{ }^{\circ} \mathrm{C}\right.$, using liquid $\mathrm{N}_{2}$ as the refrigerant) using a Micromeritics ASAP 2020 analyzer. The mass of the tested samples was approximately $100 \mathrm{mg}$. Before the measurements, all samples were required to be degassed in a $\mathrm{N}_{2}$ atmosphere at $150{ }^{\circ} \mathrm{C}$ for $10 \mathrm{~h}$. The nonlocal density functional theory (NLDFT) method was adopted to determine the pore size distribution (PSD) of the chestnut buds and nests. The chemical structures of the as-obtained chestnut buds and nests were studied using an FT-IR spectrometer (Bruker VERTEX 70). The thermal behavior of the chestnut buds and nests was investigated using thermogravimetric analysis (TG) with a high resolution thermogravimetric analyzer system (Netzsch STA 449F3). The thermogravimetric analyzer was purged with $\mathrm{N}_{2}$ at a flow rate of $50 \mathrm{~mL} \mathrm{~min}{ }^{-1}$ and a heating rate of $10{ }^{\circ} \mathrm{C} \mathrm{min}^{-1}$ in the range from 50 to $700{ }^{\circ} \mathrm{C}$. A quadrupole mass spectrometer (QMS 403) was connected to the thermogravimetric analyzer to investigate the amount of water vapour generated in the heating process.

\subsection{Batch adsorption}

Batch experiments on powder $\alpha-\mathrm{Fe}_{2} \mathrm{O}_{3}$ chestnut buds and nests were employed to determine the water treatment behavior for Cd(II), which served as a typical representative of heavy metal ions in an aqueous solution. Adsorption isotherm experiments were carried out at $T=25{ }^{\circ} \mathrm{C}$ and $\mathrm{pH}=5.0$. The $\mathrm{pH}$ of the $\mathrm{Cd}(\mathrm{II})$ solutions was adjusted by $\mathrm{HCl}\left(0.1 \mathrm{~mol} \mathrm{~L}^{-1}\right)$ and $\mathrm{NaOH}(0.1 \mathrm{~mol}$ $\left.\mathrm{L}^{-1}\right)$. To study the effect of the initial $\mathrm{Cd}(\mathrm{II})$ concentrations on the uptake capacity of the synthesized nanostructured $\alpha-\mathrm{Fe}_{2} \mathrm{O}_{3}$, the adsorbent $(80 \mathrm{mg}$ ) was added to Cd(II) solutions of different concentrations $(20,50,75,100,150,200,250,300,350$ and 
$400 \mathrm{mg} \mathrm{L}^{-1}$ ) prepared using anhydrous cadmium chloride $\left(\mathrm{CdCl}_{2}\right)$. The adsorption reaction was carried out on a shaking table at a shaking speed of $180 \mathrm{rpm}$. After the reaction, the mixtures were centrifuged at $18000 \mathrm{rpm}$ for $20 \mathrm{~min}$ to segregate the solid and liquid phases. The concentration of Cd(II) in the supernatant liquor was measured using an atomic adsorption spectrometer (AAS, Varian Spectra AA 55, USA). Continuous adsorption-desorption cycles were conducted to study the recyclability of the $\alpha-\mathrm{Fe}_{2} \mathrm{O}_{3}$ adsorbents. The adsorbed $\mathrm{Cd}(\mathrm{II})$ was desorbed with different concentrations of citric acid $(0.01,0.02$, $0.1,0.2,0.3$ and $0.4 \mathrm{~mol} \mathrm{~L}^{-1}$ ). The desorbed adsorbents (chestnut buds and nests) were completely cleaned with distilled water to remove any residual $\mathrm{Cd}(\mathrm{II})$ and immersed into the $\mathrm{Cd}(\mathrm{II})$ solution for the next adsorption-desorption process.

\section{Results and discussion}

\subsection{Characterization of chestnut buds and nests}

The crystal structure and phase purity of the synthesized chestnut buds and nests were examined via their XRD patterns. As shown in Fig. 1, both chestnut buds and nests exhibited diffraction peaks for the (012), (104), (110), (113), (024), (116), (018), (214) and (300) planes, which were fully in agreement with those for $\alpha-\mathrm{Fe}_{2} \mathrm{O}_{3}$ powder (JCPDS card no. 80-2377). ${ }^{20}$ Besides, there is no extra diffraction peak for impurities in Fig. 1, which demonstrates that the obtained chestnut buds and nests were well crystallized. The crystallinity of chestnut buds was higher than that of nests.

SEM and TEM images of the obtained nests are shown in Fig. 2. According to Fig. 2A, the reddish brown product had a well-preserved nest-like spherical structure. The average diameter of the nest nanoparticles in this sample was approximately $400 \mathrm{~nm}$. As can be seen in one high-magnification SEM image (Fig. 2B), the surface of each typical nest nanoparticle was accumulated from large numbers of fine nanosheets. Furthermore, the clear hollow interior of a single broken nest nanoparticle can be found in the other high-magnification SEM image (Fig. 2C), which demonstrates the hollow-core construction of the as-synthesized $\alpha-\mathrm{Fe}_{2} \mathrm{O}_{3}$ nests, as in the schematic diagram illustrated in Fig. $2 \mathrm{~F}$. It can be seen in the

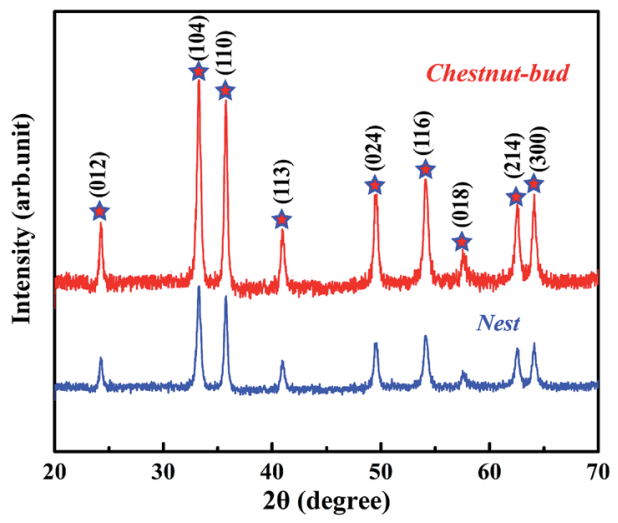

Fig. 1 XRD patterns of $\alpha-\mathrm{Fe}_{2} \mathrm{O}_{3}$ chestnut buds and nests.

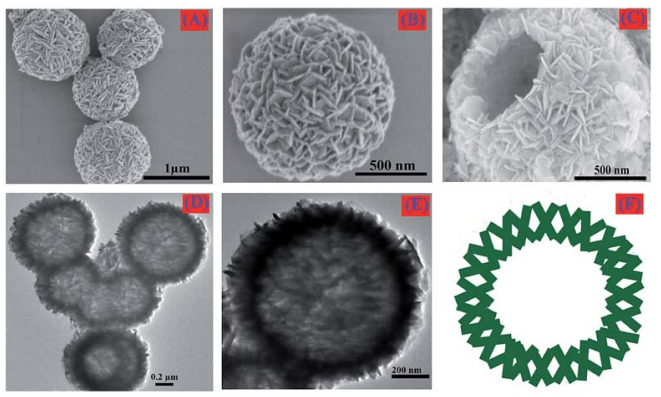

Fig. 2 (A) Low-magnification SEM image, (B, C) high-magnification SEM images, (D) TEM image, (E) HRTEM image and (F) schematic diagram of the synthesized nests.

corresponding TEM images (Fig. 2E and F) that the hollow cages possess an interlinked and uniformly stacked shell with a shell thickness of approximately $70 \mathrm{~nm}$.

The above XRD results and observations of the surface and internal structure via SEM and TEM images indicate that there are three main stages in the formation of $\alpha-\mathrm{Fe}_{2} \mathrm{O}_{3}$ nests (Fig. 3). Before the solvothermal reaction, glycerol was mixed with water to form a homogeneous quasi-reverse emulsion..$^{32}$ Despite the fact that these two kinds of solvent are mutually soluble and form a completely uniform aqueous system from the point of view of thermodynamic equilibrium, it has been found that such polar solutes as acetone, 2-propanol and butanol, etc. are liable to self-assemble in an aqueous solution because of the self-hydrophobic interactions of the alcohols, which therefore generates typical microheterogeneities in the mixed system. The quasi-reverse emulsion of water/glycerol that is formed further develops numerous emulsified spherical droplets, which act as soft templates for the construction of the shell backbone. In the solvothermal reaction, many $\mathrm{Fe}_{2} \mathrm{O}_{3}$ nanoparticles were created and assembled on the surface of these quasi-reverse-emulsion droplets by the hydrolysis of $\mathrm{FeSO}_{4} \cdot 7 \mathrm{H}_{2} \mathrm{O}$ at the appropriate reaction temperature $\left(120{ }^{\circ} \mathrm{C}\right)$ and $\mathrm{pH}$. The weakly alkaline conditions were adjusted by $\mathrm{CO}\left(\mathrm{NH}_{2}\right)_{2}$. As the hydrothermal treatment proceeded, these random nanoparticles gradually aggregated into sheet-like nanostructures to reduce the surface energy to the greatest extent and shape firm shells. Finally, the internal glycerol

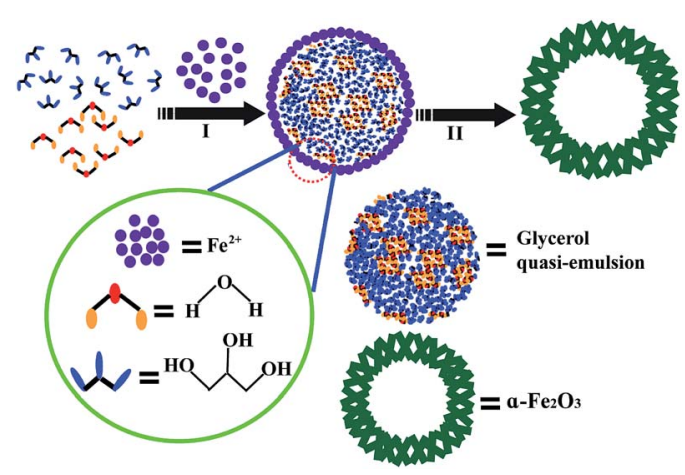

Fig. 3 Schematic illustration of the formation of $\alpha-\mathrm{Fe}_{2} \mathrm{O}_{3}$ nests. 

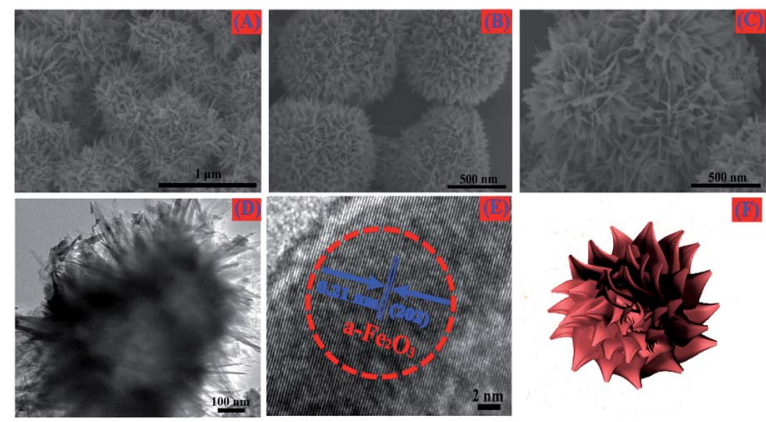

Fig. 4 (A) Low-magnification SEM image, (B, C) high-magnification SEM images, (D) TEM image, (E) HRTEM image and (F) schematic diagram of the synthesized chestnut buds.

droplets are readily removed via washing with ethanol while the skeleton of the outer shell retains its original form, which gives rise to the generation of a well-defined hollow sphere.

Fig. 4A-C shows typical SEM images of the $\alpha-\mathrm{Fe}_{2} \mathrm{O}_{3}$ chestnut buds, which are formed with a well-preserved chestnut bud-like spherical nanostructure. The $\alpha-\mathrm{Fe}_{2} \mathrm{O}_{3}$ chestnut buds are approximately $5 \mu \mathrm{m}$ in diameter and consist of hierarchical porous spheres, which are formed from enormous neatly arranged nanorods as the basic compositional units with a typical diameter of $30 \mathrm{~nm}$ and a length of 100-150 nm. A TEM image (Fig. 4D) demonstrates that the spherical $\alpha-\mathrm{Fe}_{2} \mathrm{O}_{3}$ chestnut bud has a hollow interior (as illustrated in Fig. 4F) and the outer and inner diameters of the chestnut bud-like hollow sphere are approximately $1 \mu \mathrm{m}$ and $500 \mathrm{~nm}$, respectively. From Fig. 4E, we can observe that the distance of approximately $0.210 \mathrm{~nm}$ between typical adjacent lattice fringes well corresponds to the $d$-spacing value of (202) planes in the hexagonal $\alpha$ $\mathrm{Fe}_{2} \mathrm{O}_{3}$ structure.

The formation mechanism of the $\alpha-\mathrm{Fe}_{2} \mathrm{O}_{3}$ chestnut buds is shown in Fig. 5 . The formation process of chestnut buds was the same as that of nests. The main differences involved the alcohol used as the starting material, the temperature of the solvothermal reaction and the reaction time. The growth pattern of chestnut buds and nests was in agreement with the report by Yang and Zeng. ${ }^{32}$ It was indicated that the structure and morphology of the shell skeleton were affected by the alcohol

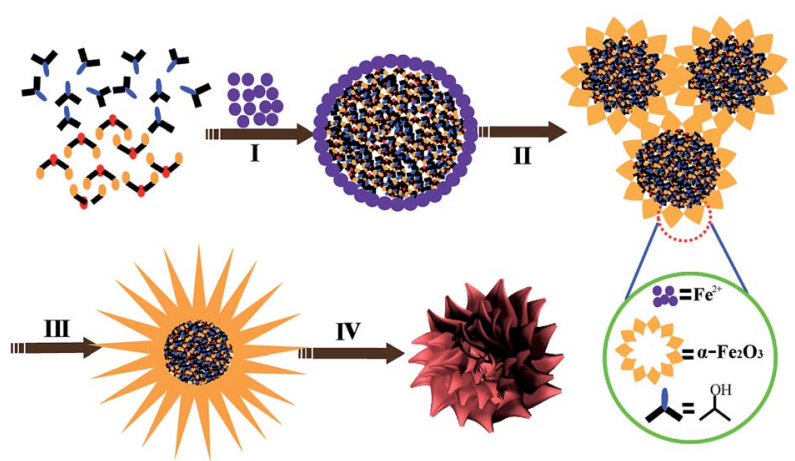

Fig. 5 Schematic illustration of the formation of $\alpha-\mathrm{Fe}_{2} \mathrm{O}_{3}$ chestnut buds.

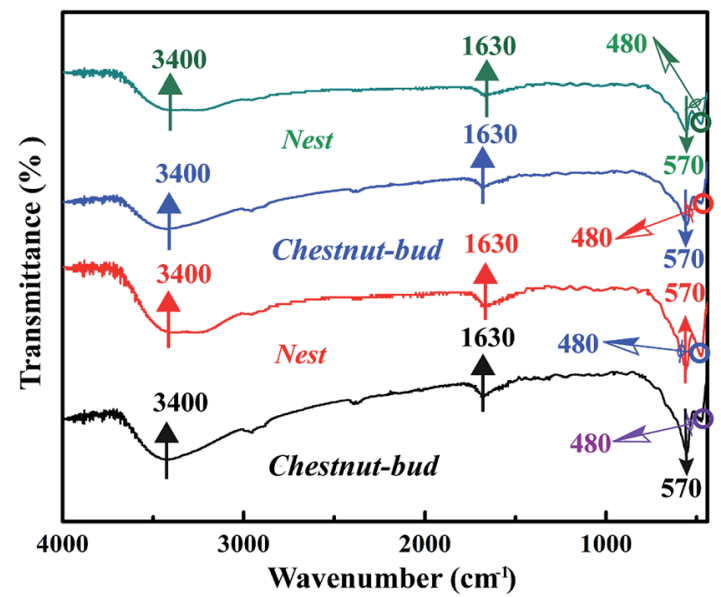

Fig. 6 FT-IR spectra of $\alpha-\mathrm{Fe}_{2} \mathrm{O}_{3}$ samples annealed at different temperatures: (a) chestnut buds: $80^{\circ} \mathrm{C}$, (b) nests: $80^{\circ} \mathrm{C}$, (c) chestnut buds: $170^{\circ} \mathrm{C}$ and (d) nests: $170{ }^{\circ} \mathrm{C}$.

used and the reaction temperature. On the one hand, the hydrophobicity of glycerol is higher than that of 2-propanol. The stronger hydrophobic interactions of glycerol would give rise to larger "micelles", which generated a larger hollow interior structure in the chestnut buds. On the other hand, both the reaction temperature $\left(150{ }^{\circ} \mathrm{C} v s .120^{\circ} \mathrm{C}\right)$ and the reaction time $(20 \mathrm{~h}$ vs. $15 \mathrm{~h})$ in the solvothermal treatment process for chestnut buds were higher than those for nests and gave rise to rougher, smoother and sharper edges and corners. All these factors led to the formation of chestnut bud-like nanostructures.

Fig. 6 shows the FT-IR spectra of the chestnut buds and nests. The broad band situated at $3400 \mathrm{~cm}^{-1}$ is assigned to the asymmetrical and symmetrical $\mathrm{O}-\mathrm{H}$ stretching vibrations of surface $\mathrm{OH}$ groups and lattice water molecules..$^{33,34}$ The strong peaks in the regions of 480 and $570 \mathrm{~cm}^{-1}$ correspond to the $\mathrm{Fe}-$ $\mathrm{O}$ stretching vibrational mode in crystalline $\alpha-\mathrm{Fe}_{2} \mathrm{O}_{3}{ }^{35}$ The presence of the peak near $1630 \mathrm{~cm}^{-1}$ is attributed to the bending vibrations of $\mathrm{Fe}-\mathrm{OH}$. The broad band at $3400 \mathrm{~cm}^{-1}$ disappeared upon annealing at $170{ }^{\circ} \mathrm{C}$, which indicates that the

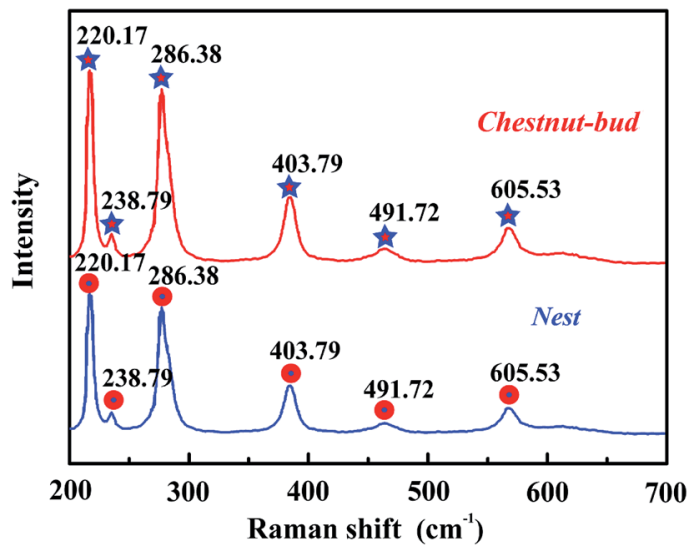

Fig. 7 Raman spectra of $\alpha-\mathrm{Fe}_{2} \mathrm{O}_{3}$ chestnut buds and nests. 
adsorbed water on the surface of the chestnut buds and nests was dislodged by heating, but the peak at $1630 \mathrm{~cm}^{-1}$ corresponding to the bending vibrations of $\mathrm{Fe}-\mathrm{OH}$ was still present, which would guarantee the effective adsorption of Cd(II).

Fig. 7 shows the Raman spectra of chestnut buds and nests, which may reflect the microstructure of the obtained nanoparticles. Obviously, there are six strong resonance peaks at positions of 220.17, 238.79, 286.38, 403.79, 491.72 and 605.53 $\mathrm{cm}^{-1}$ in the range from 200 to $700 \mathrm{~cm}^{-1}$, which are in good agreement with the typical characteristic bands observed for $\alpha$ $\mathrm{Fe}_{2} \mathrm{O}_{3}$. The resonance peaks situated at 220.17 and $491.72 \mathrm{~cm}^{-1}$ correspond to the $\mathrm{A}_{1 \mathrm{~g}}$ Raman modes, and the characteristic peaks at 238.79, 286.38, 403.79 and $605.53 \mathrm{~cm}^{-1}$ are assigned to the $\mathrm{E}_{2 \mathrm{~g}}$ Raman modes. ${ }^{36}$ It is clear that the Raman data match well with the FT-IR results.

Analysis of the $\mathrm{N}_{2}$ adsorption-desorption isotherms (Fig. 8) was performed to determine the specific surface area and structural characteristics of pores of the produced $\alpha-\mathrm{Fe}_{2} \mathrm{O}_{3}$ chestnut buds and nests. The curves exhibit hysteresis loops in the range of relative pressures of $0.80-0.98$, which indicates the presence of mesopores and micropores in the chestnut buds and nests. Both samples display type II isotherms and their BET surface areas were calculated to be 424.3 and $169.9 \mathrm{~m}^{2} \mathrm{~g}^{-1}$, respectively. Their average pore volumes are 1.09 and $0.38 \mathrm{~cm}^{3}$ $\mathrm{g}^{-1}$, respectively, and their average pore sizes are 5.04 and $6.85 \mathrm{~nm}$, respectively. The narrow pore size distribution for both samples, in particular the chestnut buds, relates to their homogeneous morphologies. The meso/micropores and large specific surface areas of the hollow spherical nanostructures would provide fast ion transportation and exchange for the adsorption/desorption of heavy metal ions in the process of wastewater treatment.
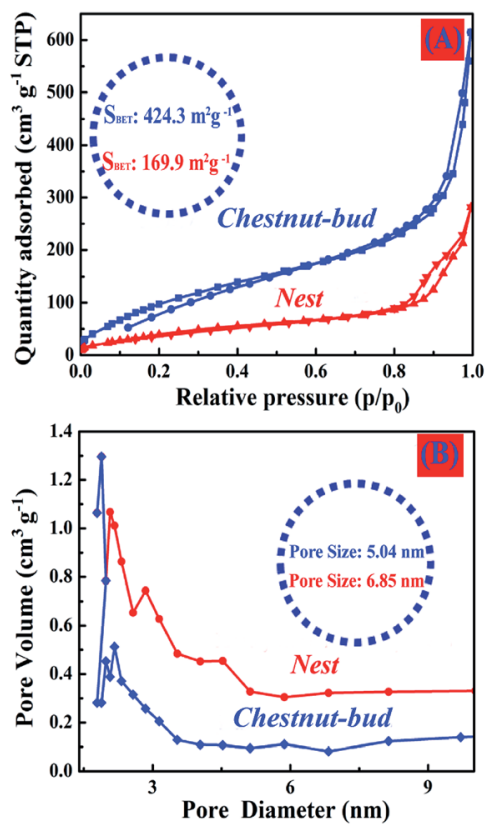

Fig. 8 (A) $\mathrm{N}_{2}$ adsorption-desorption isotherms and (B) pore size distributions of the as-synthesized hollow spherical $\alpha-\mathrm{Fe}_{2} \mathrm{O}_{3}$ nanoparticles.
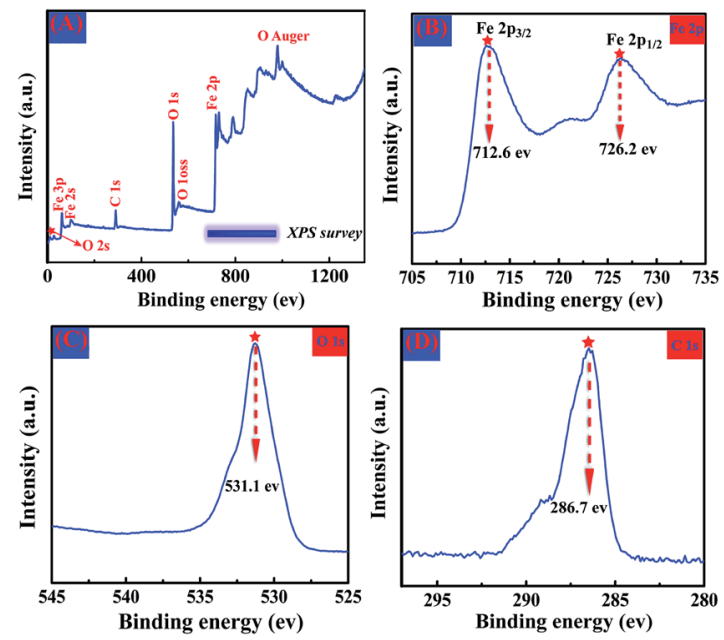

Fig. 9 Wide-scan XPS survey spectrum (A), Fe 2p XPS spectrum (B), O 1s XPS spectrum (C) and C 1s XPS spectrum (D) of the $\alpha-\mathrm{Fe}_{2} \mathrm{O}_{3}$ sample.

XPS measurements were used to perform a fundamental analysis of the elemental composition and chemical state of the produced $\alpha-\mathrm{Fe}_{2} \mathrm{O}_{3}$ samples, and the results are displayed in Fig. 9, as exemplified by chestnut buds. Fig. 9A illustrates the wide-scan survey spectrum of $\alpha-\mathrm{Fe}_{2} \mathrm{O}_{3}$ chestnut buds, which clearly indicates the presence of $\mathrm{Fe}, \mathrm{O}$ and $\mathrm{C}$ elements. Fig. 9B shows the XPS spectrum of $\mathrm{Fe}$, which includes peaks for $\mathrm{Fe} 2 \mathrm{p}_{1 / 2}$ and $\mathrm{Fe} 2 \mathrm{p}_{3 / 2}$ with binding energies located around $726.2 \mathrm{eV}$ and $712.6 \mathrm{eV}$, respectively. This indicates that the oxidation state of Fe is in the form of Fe(III) in the produced compound. ${ }^{37}$ Fig. 9C illustrates the XPS spectrum of O. Only a single peak for O $1 \mathrm{~s}$ located around $531.1 \mathrm{eV}$ is observed. This suggests that there were no impurity species in the produced sample within the sensitivity of the technique. Only a C 1s peak of surface adsorbed carbon located around $286.7 \mathrm{eV}$ (Fig. 9D) was present. ${ }^{38}$ The above results agree well with the XRD results, namely, that the obtained samples are a pure $\alpha-\mathrm{Fe}_{2} \mathrm{O}_{3}$ phase.

The chestnut buds and nests were further investigated by TG-MS. The gas detected in this procedure was $\mathrm{H}_{2} \mathrm{O}$. The profiles of the evolution of $\mathrm{H}_{2} \mathrm{O}$ upon heating for chestnut buds and nests are displayed in Fig. 10. It can be observed that the signals of water are different between chestnut buds and nests. Fig. 10A shows the profiles of the evolution of $\mathrm{H}_{2} \mathrm{O}(\mathrm{m} / \mathrm{z}=18)$ during the degradation of the chestnut buds. The first signal of weight loss is located at $95.3^{\circ} \mathrm{C}$, and the peak in the temperature region below $95.3{ }^{\circ} \mathrm{C}$ is related to the release of moisture adsorbed on the samples. The major weight loss above $200{ }^{\circ} \mathrm{C}$ can be assigned to the dehydration of $\mathrm{Fe}-\mathrm{OH}$ groups. The decomposition profiles of $\mathrm{H}_{2} \mathrm{O}(\mathrm{m} / \mathrm{z}=18)$ for nests are displayed in Fig. 10B. The peak at below $92.2{ }^{\circ} \mathrm{C}$ is associated with the evolution of moisture in the samples. Obviously, the peak signal was broader and less intense in the temperature region above $200{ }^{\circ} \mathrm{C}$, which demonstrated that the dehydration of $\mathrm{Fe}-\mathrm{OH}$ groups in nests was much less extensive than that in chestnut buds. The FT-IR and TG-MS results are in good agreement with each other, all of which indicate the presence of $\mathrm{Fe}-\mathrm{OH}$ groups in the produced $\alpha-\mathrm{Fe}_{2} \mathrm{O}_{3}$ nanostructures. 

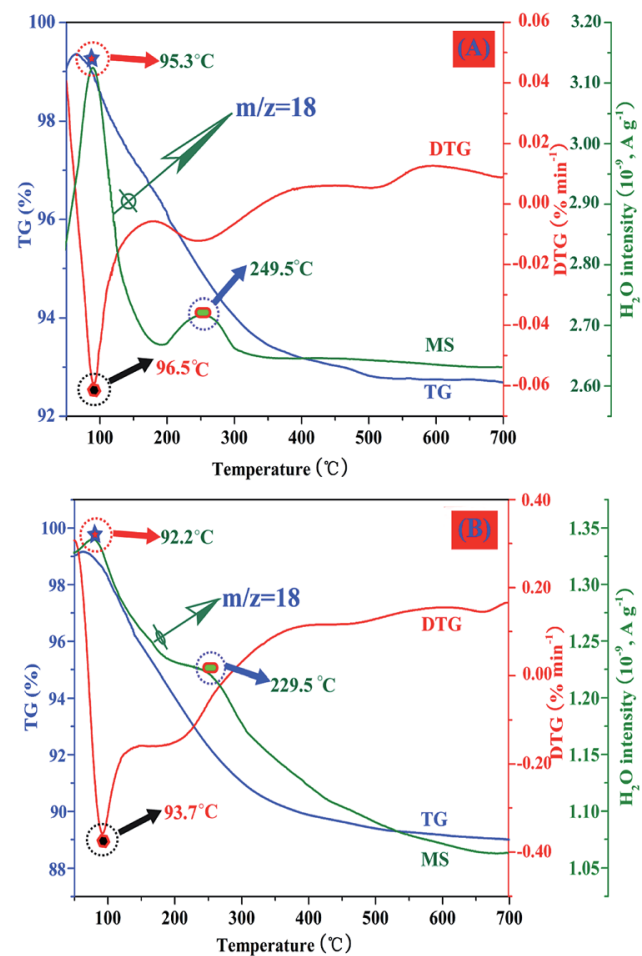

Fig. 10 Characteristic TG-MS curves for (A) chestnut buds and (B) nests.

\section{2. $\quad \mathrm{Cd}(\mathrm{II})$ adsorption studies}

$\mathrm{Cd}(\mathrm{II})$, as one of the commonest heavy metal ions, is highly toxic in industrial effluents, and the effective removal of Cd(II) from water is significantly important for environmental remediation. Here, we examined the application of the as-synthesized $\alpha$ $\mathrm{Fe}_{2} \mathrm{O}_{3}$ chestnut buds and nests in the control of environmental pollution. Fig. 11 clearly illustrates the procedure of wastewater treatment by the $\alpha-\mathrm{Fe}_{2} \mathrm{O}_{3}$ nanoparticles, which has the advantages of being facile, environment-friendly and applicable on a large scale.

The removal percentage $R(\%)$, the adsorption capacity $q_{t}(\mathrm{mg}$ $\mathrm{g}^{-1}$ ) for $\mathrm{Cd}(\mathrm{II})$ at a time $t$, and the equilibrium adsorption capacity $q_{\mathrm{e}}\left(\mathrm{mg} \mathrm{g}^{-1}\right)$ for $\mathrm{Cd}(\mathrm{II})$ adsorbed onto the chestnut buds and nests from aqueous media at $25{ }^{\circ} \mathrm{C}$ were calculated using the following equations:

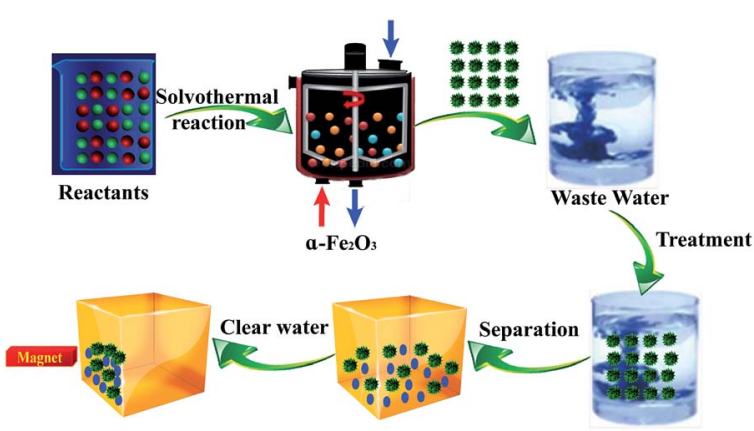

Fig. 11 Use of $\alpha-\mathrm{Fe}_{2} \mathrm{O}_{3}$ nanoparticles for wastewater treatment.

$$
\begin{gathered}
R=\frac{C_{0}-C_{t}}{C_{0}} \times 100, \\
q_{t}=\frac{\left(C_{0}-C_{t}\right) V}{m}, \\
q_{\mathrm{e}}=\frac{\left(C_{0}-C_{\mathrm{e}}\right) V}{m},
\end{gathered}
$$

where $C_{0}\left(\mathrm{mg} \mathrm{L}^{-1}\right), C_{t}\left(\mathrm{mg} \mathrm{L}^{-1}\right)$ and $C_{\mathrm{e}}\left(\mathrm{mg} \mathrm{L}^{-1}\right)$ represent the initial concentration, concentration at a time $t$ and equilibrium concentration, respectively, of the $\mathrm{Cd}(\mathrm{II})$ solution, $V(\mathrm{~L})$ is the volume of the Cd(II) solution and $m$ (g) represents the mass of the adsorbent used in the batch adsorption procedure.

3.2.1. Effect of contact time. The effect of the contact time on the uptake of $\mathrm{Cd}$ (II) by chestnut buds and nests was studied to ascertain the time required to reach equilibrium in the adsorption reaction (Fig. 12). (The initial concentration of the Cd(II) solutions was $300 \mathrm{mg} \mathrm{L}^{-1}$, the initial $\mathrm{pH}$ was 5 and the adsorption reactions were conducted at $25{ }^{\circ} \mathrm{C}$.) At the initial stage $(30 \mathrm{~min})$, it is clearly observed from Fig. $12 \mathrm{~A}$ that the rate of adsorption of $\mathrm{Cd}$ (II) onto chestnut buds was very rapid. When the adsorption reaction was continued for $60-80 \mathrm{~min}$, the relative adsorption capacity for $\mathrm{Cd}$ (II) underwent no significant increase, which indicated that adsorption equilibrium was established within $100 \mathrm{~min}$. During this period, the chestnut buds displayed superior capability for the removal of $\mathrm{Cd}(\mathrm{II})$; almost $93.7 \%$ of $\mathrm{Cd}(\mathrm{II})$ was removed. The rapid adsorption of Cd(II) by chestnut buds may indicate that most of their active sites are exposed for the adsorption of Cd(II). Hence, a contact time of $100 \mathrm{~min}$ is suitable for the maximum adsorption of Cd(II) by chestnut buds.

As shown in Fig. 12B, the rate of removal of $\mathrm{Cd}(\mathrm{II})$ for nests was lower than that for chestnut buds. The appropriate contact
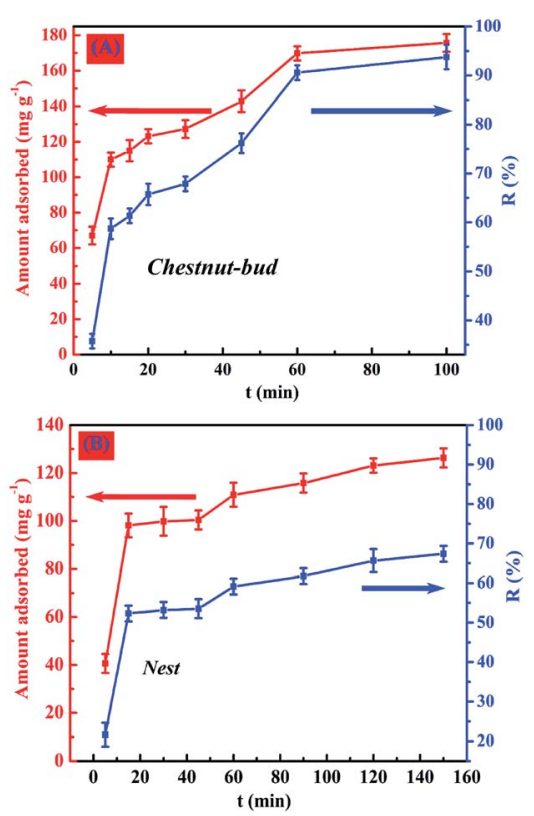

Fig. 12 Effect of contact time on adsorption capacity for $\mathrm{Cd}(\Perp)$ of (A) chestnut buds and (B) nests. 

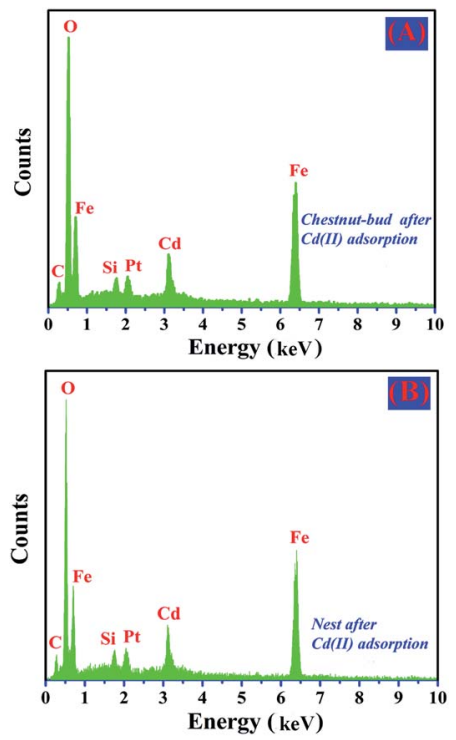

Fig. 13 EDX spectra of (A) chestnut buds after adsorption of $\mathrm{Cd}(॥)$ and (B) nests after adsorption of $\mathrm{Cd}(\Perp)$.

time taken for nests to reach adsorption equilibrium was $150 \mathrm{~min}$, which was longer than that for chestnut buds. Furthermore, only $67.4 \%$ of $\mathrm{Cd}(\mathrm{II})$ was removed by the nests after $150 \mathrm{~min}$. The difference in the rate of adsorption for the uptake of $\mathrm{Cd}(\mathrm{II})$ between the chestnut buds and nests was potentially due to the different numbers of available active adsorption sites. With an increase in the contact time the adsorption sites gradually became exhausted, and afterwards the adsorption rate declined as a result of the slow pore diffusion of Cd(II) into the bulk of the chestnut buds and nests.

After the adsorption of Cd(II), EDX and XPS analyses were performed to determine the elemental compositions of chestnut buds and nests. As shown in Fig. 13, the EDX results indicate the presence of $\mathrm{Fe}, \mathrm{O}$ and $\mathrm{Cd}$ elements in the chestnut

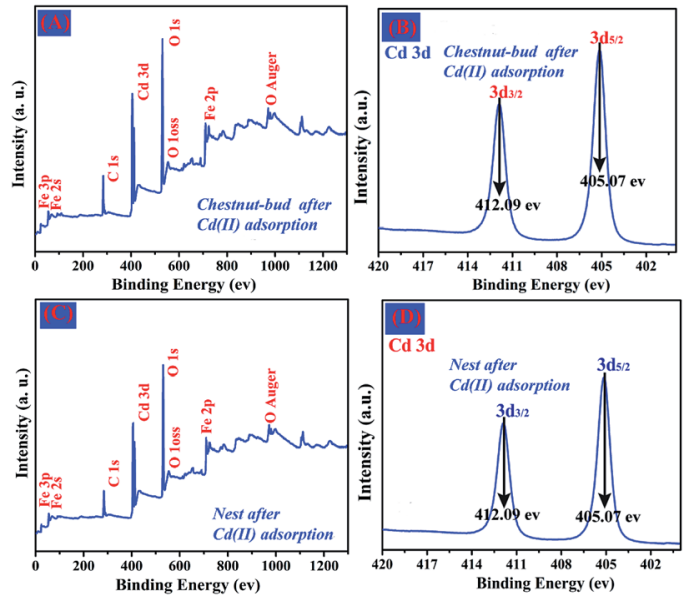

Fig. 14 (A) Wide-scan XPS survey spectrum of chestnut buds after adsorption of $\mathrm{Cd}(\mathrm{I}),(\mathrm{B})$ the corresponding $\mathrm{Cd} 3 \mathrm{~d}$ XPS spectrum, (C) wide-scan XPS survey spectrum of nests after adsorption of $\mathrm{Cd}(॥)$, (D) the corresponding Cd $3 d$ XPS spectrum. buds and nests after the adsorption of $\mathrm{Cd}(\mathrm{II})$. The average atomic weight percentage ratios of $\mathrm{Fe}: \mathrm{O}: \mathrm{Cd}$ for the tested chestnut buds and nests were $31.8: 59.9: 8.6$ and $35.4: 56.5: 8.1$, respectively.

Fig. 14A and C show the wide-scan survey spectra of chestnut buds and nests after the adsorption of Cd(II). They also clearly indicate the presence of $\mathrm{Fe}, \mathrm{O}$ and $\mathrm{Cd}$ elements. Peaks for $\mathrm{Cd}$ $3 \mathrm{~d}_{3 / 2}$ and $\mathrm{Cd} 3 \mathrm{~d}_{5 / 2}$ had binding energies located around $412.09 \mathrm{eV}$ and $405.07 \mathrm{eV}$, respectively (Fig. 14B and D). They indicate that the oxidation state of $\mathrm{Cd}$ is in the form of $\mathrm{Cd}(\mathrm{II})$ in the produced compound. ${ }^{39}$ The above XPS results are in good agreement with the EDX results, namely, that the heavy metal ion Cd(II) has been adsorbed onto the as-synthesized chestnut buds and nests.

3.2.2. Effect of initial $\mathbf{p H}$. The $\mathrm{pH}$ value of the external Cd(II) solution affects the activity of functional groups on the surface of adsorbents. The adsorption capacity for Cd(II) of chestnut buds and nests as a function of the initial $\mathrm{pH}$ is illustrated in Fig. 15. (The initial concentration of the $\mathrm{Cd}(\mathrm{II})$ solutions was $300 \mathrm{mg} \mathrm{L}^{-1}$ and the adsorption reactions were conducted at $25{ }^{\circ} \mathrm{C}$. The contact times for chestnut buds and nests were 100 and $150 \mathrm{~min}$, respectively.) As can be seen in Fig. 15, the adsorption capacity for Cd(II) of both adsorbents is critically dependent upon the $\mathrm{pH}$ of the $\mathrm{Cd}(\mathrm{II})$ solution. In addition, the adsorption capacity for Cd(II) of the chestnut buds is much higher than that of the nests at all $\mathrm{pH}$ values $(1.0,2.0$, 3.0, 4.0, 5.0 and 6.0). With an increase in $\mathrm{pH}$ in the range from 1.0 to 6.0 , the adsorption capacity for Cd(II) of chestnut buds increased from 54.1 to $175.8 \mathrm{mg} \mathrm{g}^{-1}$, and from 25.2 to $126.3 \mathrm{mg}$ $\mathrm{g}^{-1}$ for nests. The adsorption capacity for $\mathrm{Cd}(\mathrm{II})$ of both chestnut buds and nests underwent a prompt increase when the solution $\mathrm{pH}$ was $1.0-3.0$, followed by a slow increase at $\mathrm{pH}$ values of 3.05.0 to an almost constant level at a pH of 5.0-6.0. These results indicated that the optimum adsorption capacities for Cd(II) of chestnut buds and nests can be obtained in the $\mathrm{pH}$ range of 5.0-6.0.

The change in adsorption capacity for Cd(II) with the change in $\mathrm{pH}$ can be explained by considering the point of zero charge (PZC) of the adsorbents. The $\mathrm{pH}_{\mathrm{PzC}}$ values of chestnut buds and nests are 4.9 and 5.2, respectively, which were determined from

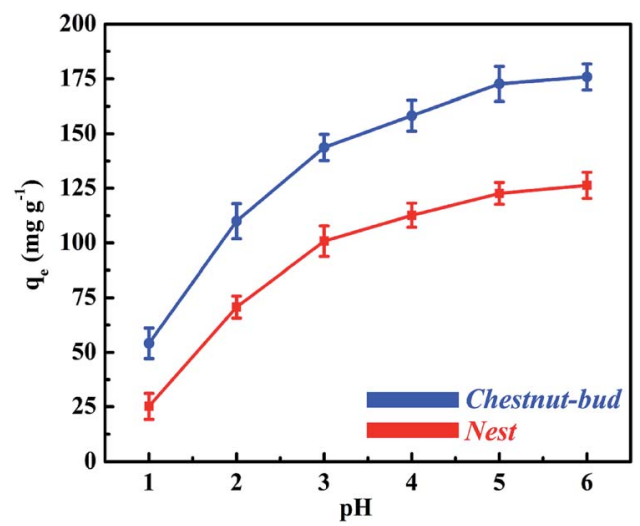

Fig. 15 Effect of initial $\mathrm{pH}$ value on adsorption capacity for $\mathrm{Cd}(॥)$ of chestnut buds and nests. 
measurements of the zeta potential. The available active sites on the adsorbents for the efficient removal of heavy metals are derived from hydrogen ions in hydroxyl groups. ${ }^{40}$ Determination of the form in which $\mathrm{Cd}$ (II) is present in solutions with different $\mathrm{pH}$ values is complex, because there are multiple $\mathrm{Cd}$ (II) species present in solutions. When the adsorption process takes place, each divalent $\mathrm{Cd}(\mathrm{II})$ ion displaces one proton from $-\mathrm{OH}$ groups via electrostatic attraction (ion exchange) to generate $\mathrm{Cd}(\mathrm{OH})^{+}$species. At a $\mathrm{pH}$ below the $\mathrm{PZC}$, the presence of large amounts of $\mathrm{H}^{+}$ions increases the repulsive forces that exist between the positively charged Cd(II) species and the adsorption sites of the adsorbents. They can be adsorbed on the negatively charged active sites on the surface of chestnut buds and nests via the protonation effect. Thus, at lower $\mathrm{pH}$ values (1.0-2.0) the adsorption capacity for $\mathrm{Cd}(\mathrm{II})$ was relatively low. After a further increase in the solution $\mathrm{pH}$, the adsorbed $\mathrm{Cd}(\mathrm{OH})^{+}$species on chestnut buds and nests continued to displace one proton to produce soluble $\mathrm{Cd}(\mathrm{OH})_{2}$. Then, the amount of adsorbed $\mathrm{Cd}(\mathrm{II})$ rose rapidly in the $\mathrm{pH}$ range from 2.0 to 3.0 , and rose gradually in the $\mathrm{pH}$ range from 3.0 to 5.0. At a $\mathrm{pH}$ above the PZC, negatively charged $\mathrm{OH}^{-}$ions exhibit strong coordinative affinity towards positively charged Cd(II) ions. The electrostatic attractive forces cause $\mathrm{OH}^{-}$ions to capture Cd(II) species via surface complexation. The level of surface complexation can be enhanced as the $\mathrm{pH}$ value increases. If the $\mathrm{pH}$ value of the solution exceeded 6.0, fewer $\mathrm{H}^{+}$ions would be able to compete with $\mathrm{Cd}(\mathrm{II})$ ions for active adsorption sites. Thus, soluble $\mathrm{Cd}(\mathrm{OH})_{2}$ species would become supersaturated and a precipitate of $\mathrm{Cd}(\mathrm{OH})_{2}$ would be generated. Thereafter, $\mathrm{Cd}(\mathrm{II})$ in the solution is taken up not only by adsorption but also by precipitation. Consequently, all subsequent adsorption experiments were conducted at the optimum initial $\mathrm{pH}$ of 5.0 to achieve the maximum adsorption capacity. At this $\mathrm{pH}$ value, ion exchange and surface complexation are the predominant mechanisms for the removal of metal ions from solution.

3.2.3. Effect of initial Cd(II) concentration. Fig. 16 shows the removal performance for $\mathrm{Cd}(\mathrm{II})$ with different initial concentrations of the chestnut buds and nests. (The initial $\mathrm{pH}$ of the Cd(II) solutions was 5.0 and the adsorption reactions were

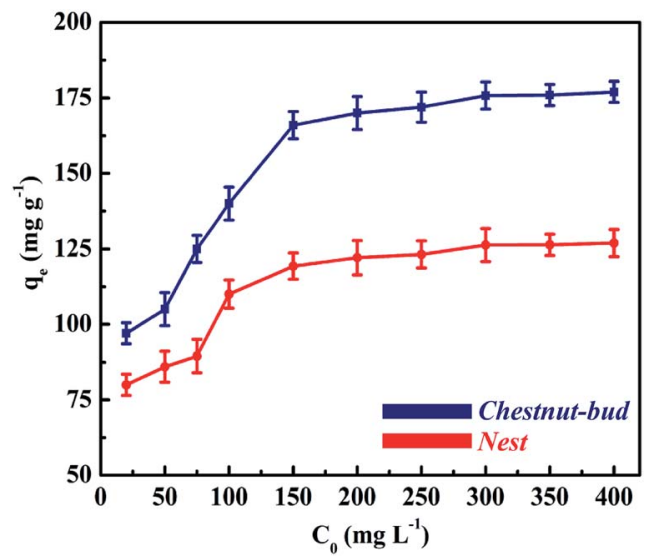

Fig. 16 Adsorption capacity for $\mathrm{Cd}(॥)$ with different initial $\mathrm{Cd}(॥)$ concentrations of chestnut buds and nests. conducted at $25{ }^{\circ} \mathrm{C}$. The contact times for chestnut buds and nests were 100 and $150 \mathrm{~min}$, respectively.) It is demonstrated that the adsorption capacity of chestnut buds when reaching an equilibrium state increased rapidly as the initial concentration of Cd(II) increased from 20 to $300 \mathrm{mg} \mathrm{L}^{-1}$, which indicates that the removal behavior for $\mathrm{Cd}(\mathrm{II})$ did not achieve adsorption saturation in this initial concentration range. The adsorption capacity remained nearly stable as the $\mathrm{Cd}$ (II) concentration continued to increase (300-400 $\mathrm{mg} \mathrm{L}^{-1}$ ), which indicated that the active adsorption sites were not sufficient for the adsorption reaction. A similar isotherm curve is also observed for the nests, but the curve for the chestnut buds is much higher and steeper. For the chestnut buds, the removal capacity for $\mathrm{Cd}(\mathrm{II})$ increased from 97 to $175.8 \mathrm{mg} \mathrm{g}^{-1}$ when the initial Cd(II) concentration increased from 20 to $400 \mathrm{mg} \mathrm{L}^{-1}$, whereas it increased from 80 to $126.3 \mathrm{mg} \mathrm{g}^{-1}$ for the nests. The maximum adsorption capacity of the chestnut buds for $\mathrm{Cd}(\mathrm{II})$ was found to be $175.8 \mathrm{mg} \mathrm{g}^{-1}$ in comparison to $126.3 \mathrm{mg} \mathrm{g}^{-1}$ for the nests. The surfaces of $\alpha-\mathrm{Fe}_{2} \mathrm{O}_{3}$ nanoparticles can afford large amounts of active adsorption sites and are beneficial for the transportation and complexation of $\mathrm{Cd}(\mathrm{II})$. The different structures of the chestnut buds and nests and their different specific surface areas (424.3 and $169.9 \mathrm{~m}^{2} \mathrm{~g}^{-1}$, respectively) led to different numbers of active adsorption sites.

3.2.4. Effect of other coexisting metal ions. To investigate the selectivity behavior for heavy metal ions in a multicomponent system, the removal percentages of chestnut buds for three different heavy metal ions, i.e., $\mathrm{Cd}$ (II), $\mathrm{Zn}$ (II) and $\mathrm{Ni(II),}$ in single-component, binary and ternary solutions were examined (Fig. 17). The concentration of each metal was $300 \mathrm{mg} \mathrm{L}^{-1}$ and the amount of the adsorbents was $80 \mathrm{mg}$. The initial $\mathrm{pH}$ of the metal ion solution was 5.0 and the adsorption reactions were conducted at $25{ }^{\circ} \mathrm{C}$. The contact time was $240 \mathrm{~min}$. As illustrated in Fig. 17, the removal percentages for $\mathrm{Cd}(\mathrm{II}), \mathrm{Ni}$ (II) and $\mathrm{Zn}$ (II) in single-component systems were $93.7 \%, 76.8 \%$ and $38.3 \%$, respectively. In binary systems (Cd(II)-Zn(II) and Cd(II)$\mathrm{Ni}(\mathrm{II})$ ), the removal percentages for $\mathrm{Cd}(\mathrm{II})$ of chestnut buds were

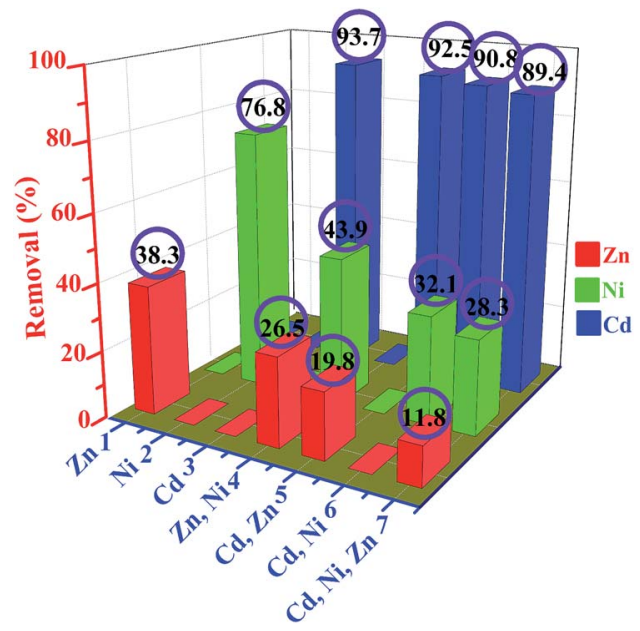

Fig. 17 Removal percentages for $\mathrm{Cd}(॥), \mathrm{Zn}(॥)$ and $\mathrm{Ni}(॥)$ from singlecomponent, binary and ternary ion solutions. 
92.5\% and $90.8 \%$, respectively, in the presence of $\mathrm{Zn}$ (II) or $\mathrm{Ni}$ (II). In comparison, the removal percentages for $\mathrm{Zn}$ (II) and $\mathrm{Ni}$ (II) displayed sharp declines (to $19.8 \%$ and $32.1 \%$, respectively) in the same binary solutions. This clearly suggests that Cd(II) was preferentially adsorbed onto the surface of chestnut buds in comparison to $\mathrm{Ni}$ (II) or $\mathrm{Zn}$ (II). In the case of the binary $\mathrm{Ni(II)-}$ $\mathrm{Zn}$ (II) system, it was observed that the removal percentages for $\mathrm{Ni}$ (II) and $\mathrm{Zn}$ (II) were also reduced to $43.9 \%$ and $26.5 \%$, respectively, which indicates the competitiveness of the two metal ions. As can be seen in the case of the ternary ion solutions, the removal percentages for $\mathrm{Cd}(\mathrm{II}), \mathrm{Ni}(\mathrm{II})$ and $\mathrm{Zn}$ (II) were $89.4 \%, 43.9 \%$ and $26.5 \%$, respectively. In compared with the cases of single-component or binary ion solutions, the removal efficiency for $\mathrm{Cd}(\mathrm{II})$ maintained a relatively stable level. Nevertheless, the removal efficiency for Ni(II) and $\mathrm{Zn}$ (II) was much less than that in the single-component or binary systems. According to the comparative results from the single-component, binary and ternary systems, it is revealed that the influence of the coexistence of $\mathrm{Ni}$ (II) and/or $\mathrm{Zn}$ (II) on the adsorption of $\mathrm{Cd}$ (II) by chestnut buds was negligible, whereas the removal efficiencies for $\mathrm{Zn}$ (II) and $\mathrm{Ni}$ (II) greatly decreased when in a competitive metal ion environment. Thus, the removal efficiencies for the three metal ions follow the order of $\mathrm{Cd}$ (II) $>\mathrm{Ni}$ (II) $>\mathrm{Zn}$ (II), which suggests a stronger affinity of the chestnut buds for Cd(II) than for Ni(II) and $\mathrm{Zn}$ (II).

\subsection{Adsorption mechanism and kinetics}

The as-synthesized nanostructured $\alpha-\mathrm{Fe}_{2} \mathrm{O}_{3}$ particles, in particular the chestnut buds, exhibited high adsorption performance with a maximum adsorption capacity of $175.8 \mathrm{mg} \mathrm{g}^{-1}$ and a removal percentage of $93.7 \%$ within $100 \mathrm{~min}$ of the adsorption reaction. Their superior properties strictly depend on their microstructure. Fig. 18 illustrates the structural characteristics of the hollow spheres of $\alpha-\mathrm{Fe}_{2} \mathrm{O}_{3}$ nanoparticles, which can be summarized as follows. First of all, both adsorbents possess hierarchically porous hollow structures with an average pore size of 5.04 and $6.85 \mathrm{~nm}$, respectively, as investigated by $\mathrm{N}_{2}$ adsorption and desorption isotherms, which indicates that micropores and mesopores constituted the major pore components. The mesopores in the hollow spherical shell are

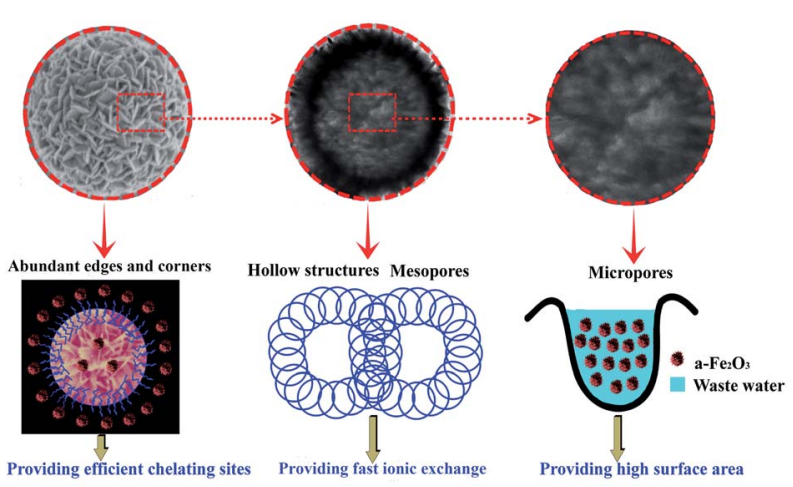

Fig. 18 Schematic illustration of the structural characteristics of the hollow spheres of $\alpha-\mathrm{Fe}_{2} \mathrm{O}_{3}$ nanoparticles. beneficial for providing rapid ion exchange and a high complexation rate because of the easy permeation and transportation of $\mathrm{Cd}$ (II) into the surface and interior of the hollow spheres. Moreover, the micropores can provide a large surface area, namely, large amounts of active adsorption sites. Finally, the abundant edges and corners on the surfaces of the hollow spheres can provide efficient chelating sites to ensure the effective adsorption of $\mathrm{Cd}(\mathrm{II})$.

Fig. 19 illustrates the process of the adsorption of $\mathrm{Cd}(\mathrm{II})$ by nanostructured $\alpha-\mathrm{Fe}_{2} \mathrm{O}_{3}$ adsorbents. The mechanism of the removal of $\mathrm{Cd}(\mathrm{II})$ included surface complexation and ion exchange between the surface $\mathrm{OH}$ groups of the adsorbents and the heavy metal ions of the adsorbates in the aqueous solution, in which bonding of $\mathrm{Cd}$ (II) via coordination by the $\mathrm{OH}$ groups played an indispensable role. ${ }^{9}$ The well-defined morphology of the chestnut buds led to a larger BET specific surface area and pore volume (424.3 $\mathrm{cm}^{2} \mathrm{~g}^{-1}$ and $1.09 \mathrm{~cm}^{3} \mathrm{~g}^{-1}$, respectively), which were 2.50 and 2.87 times higher, respectively, than those of the nests. The homogeneous channels inside and outside the $\alpha-\mathrm{Fe}_{2} \mathrm{O}_{3}$ nanoparticles could provide abundant active adsorption sites and are thus convenient for the movement and transport of $\mathrm{Cd}(\mathrm{II})$ in the adsorption reaction.

The adsorption kinetics behavior, which governs the rate of removal of $\mathrm{Cd}$ (II) and the adsorption mechanisms in the adsorption process, is a significant factor in evaluating the efficiency of the removal of Cd(II). As shown in Fig. 12, an apparent adsorption equilibrium was reached within $100 \mathrm{~min}$ and $150 \mathrm{~min}$ for chestnut buds and nests, respectively. Three kinetics models, i.e., pseudo-first-order and pseudo-secondorder rate equations and the intraparticle diffusion model, were selected to analyze the adsorption kinetics data. ${ }^{\mathbf{4 1 , 4 2}}$

The expression for the pseudo-first-order kinetics model is as follows:

$$
\log \left(q_{\mathrm{e}}-q_{t}\right)=\log q_{\mathrm{e}}-\frac{k_{1}}{2.303} t
$$

The expression for the pseudo-second-order kinetics model is as follows:

$$
\frac{t}{q_{\mathrm{e}}}=\frac{1}{k_{2} q_{\mathrm{e}}^{2}}+\frac{1}{q_{\mathrm{e}}} t,
$$

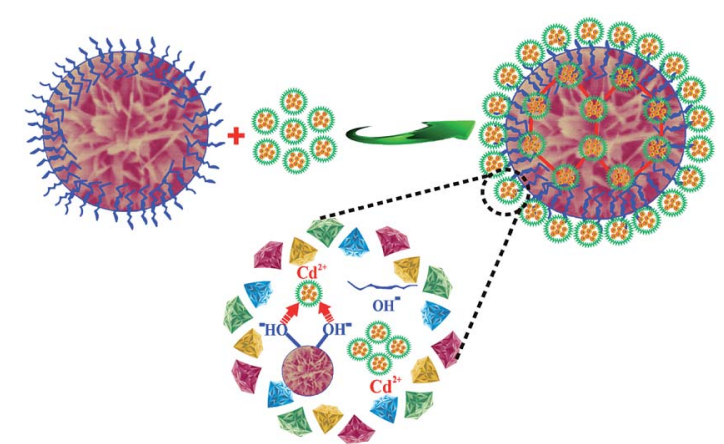

Fig. 19 Proposed mechanism of adsorption of $\mathrm{Cd}(\Perp)$ on $\alpha-\mathrm{Fe}_{2} \mathrm{O}_{3}$ nanoparticles. 
Table 1 Kinetic fitting parameters for adsorption of $\mathrm{Cd}(॥)$ on the chestnut buds and nests

\begin{tabular}{|c|c|c|c|c|c|c|c|}
\hline Sample & $q_{\mathrm{e}}(\exp )$ & \multicolumn{3}{|c|}{ Pseudo-first-order } & \multicolumn{3}{|l|}{ Pseudo-second-order } \\
\hline Nests & 126.3 & $1.91 \times 10^{-2}$ & 56.1 & 0.858 & $7.25 \times 10^{-4}$ & 132.1 & 0.996 \\
\hline
\end{tabular}

The expression of the intraparticle diffusion model is as follows:

$$
q_{t}=K_{3} t_{1 / 2}+C
$$

where $q_{\mathrm{e}}\left(\mathrm{mg} \mathrm{g}^{-1}\right)$ is the equilibrium adsorption capacity, $q_{t}(\mathrm{mg}$ $\left.\mathrm{g}^{-1}\right)$ is the adsorption capacity at a time $t(\min ), k_{1}\left(\mathrm{~min}^{-1}\right)$ and $k_{2}\left(\mathrm{~g} \mathrm{mg}^{-1} \mathrm{~min}^{-1}\right)$ are the pseudo-first-order and pseudosecond-order rate constants, respectively, $K_{3}\left(\mathrm{~g} \mathrm{mg}^{-1} \mathrm{~min}^{-1}\right)$ is the intraparticle diffusion rate constant and $C$ is the intercept.

The parameters calculated from the pseudo-second-order and pseudo-first-order kinetics models are presented in Table 1. The linear correlation coefficients $R^{2}(0.893$ and 0.858 for the chestnut buds and nests, respectively) that were determined from the pseudo-first-order model were not very satisfactory, which suggests that the pseudo-first-order model is not appropriate for fitting the experimental data as a result of a deviation from linear behavior. In comparison with the pseudo-first-order model, the pseudo-second-order model yields excellent results with higher correlation coefficients $\left(R^{2}>0.99\right)$. Therefore, it can be concluded that the adsorption of $\mathrm{Cd}$ (II) onto both adsorbents displays the best agreement with the pseudo-second-order kinetics model, which revealed that the rate-controlling step might be chemisorption.

In the intraparticle diffusion model, the rate-limiting step is diffusion-controlled. In other words, the rate of adsorption relies on the speed of diffusion of the adsorbate towards the adsorbent. The intraparticle diffusion model, as fitted with the experimental data, is shown in Fig. 20 and the parameters are listed in Table 2. The linear correlation coefficients calculated from the intraparticle diffusion model for both adsorbents are

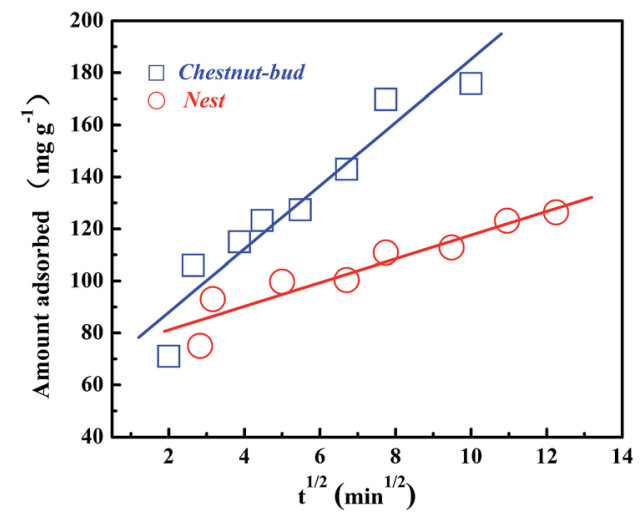

Fig. 20 Intraparticle diffusion kinetics model for removal of $\mathrm{Cd}(॥)$ by chestnut buds and nests.
Table 2 Experimental conditions and kinetic fitting parameters of intraparticle diffusion model for adsorption of $\mathrm{Cd}(॥)$ on the chestnut buds and nests

\begin{tabular}{llll}
\hline & & \multicolumn{2}{c}{ Intraparticle diffusion model } \\
\cline { 3 - 4 } Sample & $C_{0}\left(\mathrm{mg} \mathrm{L}^{-1}\right)$ & $K_{3}\left(\mathrm{~g} \mathrm{mg}^{-1} \mathrm{~min}^{-1}\right)$ & $R^{2}$ \\
\hline Chestnut buds & 300 & 12.7686 & 0.9089 \\
Nests & 300 & 4.5552 & 0.9027 \\
\hline
\end{tabular}

higher than 0.9, which reveals that the rate-controlling step might be pore diffusion. Comparing all the results of the three kinetics models, it is indicated that the rate-controlling step is a combination of chemisorption and pore diffusion.

\subsection{Adsorption isotherms}

The Langmuir and Freundlich models were employed to analyze the adsorption isotherm of $\mathrm{Cd}(\mathrm{II}){ }^{43}$ The Langmuir model considers that strong monolayer surface sorption takes place on specific homogeneous sites and no interaction occurs among the adsorbates. The expression of the Langmuir isotherm is as follows:

$$
\frac{C_{\mathrm{e}}}{q_{\mathrm{e}}}=\frac{1}{K_{\mathrm{L}} Q}+\frac{1}{Q} C_{\mathrm{e}},
$$

where $C_{\mathrm{e}}\left(\mathrm{mg} \mathrm{L}^{-1}\right)$ represents the equilibrium concentration of $\mathrm{Cd}(\mathrm{II}), q_{\mathrm{e}}\left(\mathrm{mg} \mathrm{g}^{-1}\right)$ represents the equilibrium adsorption capacity for $\mathrm{Cd}(\mathrm{II}), Q\left(\mathrm{mg} \mathrm{g}^{-1}\right)$ represents the maximum monolayer adsorption capacity of $\mathrm{Cd}(\mathrm{II})$, and $K_{\mathrm{L}}\left(\mathrm{L} \mathrm{mg}^{-1}\right)$ represents the Langmuir adsorption constant.

The Freundlich isotherm is an empirical equation, which usually describes heterogeneous surface adsorption. The common expression is as follows:

$$
\log q_{\mathrm{e}}=\log K_{\mathrm{F}}+\frac{1}{n} \log C_{\mathrm{e}}
$$

Table 3 Isotherm fitting parameters for adsorption of $\mathrm{Cd}($ (I) on the chestnut buds and nests

\begin{tabular}{lllllllll}
\hline & Langmuir & & & \multicolumn{2}{l}{ Freundlich } & \\
\cline { 2 - 3 } Sample & $q_{\mathrm{m}}\left(\mathrm{mg} \mathrm{g}^{-1}\right)$ & $K_{\mathrm{L}}\left(\mathrm{L} \mathrm{mg}^{-1}\right)$ & $R^{2}$ & & $1 / n$ & $K_{\mathrm{F}}$ & $R^{2}$ \\
\hline Chestnut buds & 184.8 & $6.31 \times 10^{-2}$ & 0.997 & 0.108 & 91.9 & 0.774 \\
Nests & 131.9 & $6.75 \times 10^{-2}$ & 0.998 & 0.121 & 62.6 & 0.839
\end{tabular}


Table 4 Maximum adsorption capacities for $\mathrm{Cd}(॥)$ of various adsorbents

\begin{tabular}{|c|c|c|c|c|}
\hline Adsorbent & $\begin{array}{l}\text { BET surface } \\
\text { area }\left(\mathrm{m}^{2} \mathrm{~g}^{-1}\right)\end{array}$ & $\begin{array}{l}\text { Removal efficiency } \\
(\%)\end{array}$ & $\begin{array}{l}\text { Maximum capacity } \\
\left(\mathrm{mg} \mathrm{g}^{-1}\right)\end{array}$ & Reference \\
\hline Chinese loess & 15 & 90 & 9.4 & 44 \\
\hline FPBS & 214.1 & 91 & 38.8 & 46 \\
\hline $\begin{array}{l}\text { Biogenic } \mathrm{Fe}_{3} \mathrm{O}_{4} \\
\text { nanocomposites }\end{array}$ & 11.3 & 96.1 & 49.1 & 47 \\
\hline$\alpha-\mathrm{Fe}_{2} \mathrm{O}_{3}$ chestnut buds & 424.3 & 93.7 & 175.8 & This work \\
\hline
\end{tabular}

where $K_{\mathrm{F}}\left(\mathrm{mg} \mathrm{g}^{-1}\right)$ and $1 / n$ represent the Freundlich constants that relate to the adsorbed amount and the adsorption intensity of the adsorbent, respectively.

The results of the Langmuir and Freundlich models, which were determined by curve fitting, are listed in Table 3. It is found that the linear correlation coefficients fitted by the Langmuir model $\left(R^{2}=0.997\right.$ and 0.998 for the chestnut buds and nests, respectively) are higher than those fitted by the Freundlich model, which indicates that the Langmuir model is preferable for describing the adsorption of $\mathrm{Cd}(\mathrm{II})$ on both adsorbents. The simulated Langmuir adsorption behavior shows that there are homogeneous active sites in the chestnut buds and nests and the adsorption process of $\mathrm{Cd}(\mathrm{II})$ is a monolayer adsorption reaction.

As listed in Table 4 and illustrated in Fig. 21, in comparison with other adsorbents reported in the literature it is obvious that the adsorbents, in particular the chestnut buds, studied in this work have superior adsorption capacities for $\mathrm{Cd}(\mathrm{II})$. Hence, the chestnut buds have great potential for the efficient removal of $\mathrm{Cd}(\mathrm{II})$ in the treatment of water pollution.

\subsection{Reusability studies}

An efficient recycling process for an adsorbent must possesses the quality of being able to simply release the adsorbate under

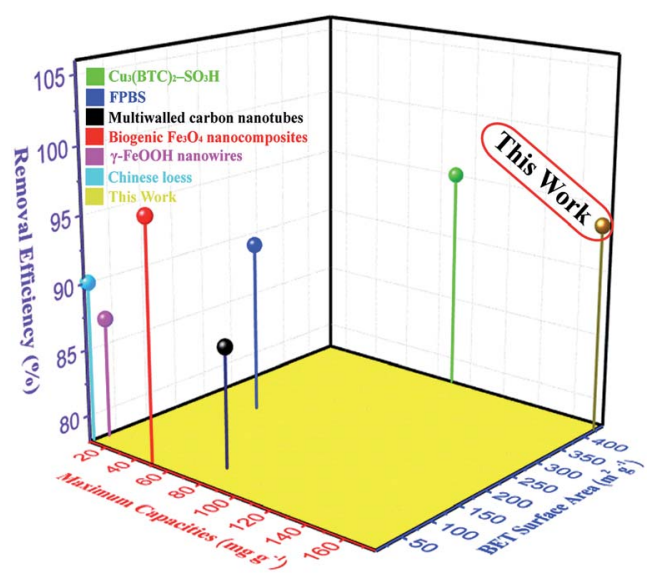

Fig. 21 Summary of adsorption capacities for $\mathrm{Cd}(॥)$ of several typical adsorbents.

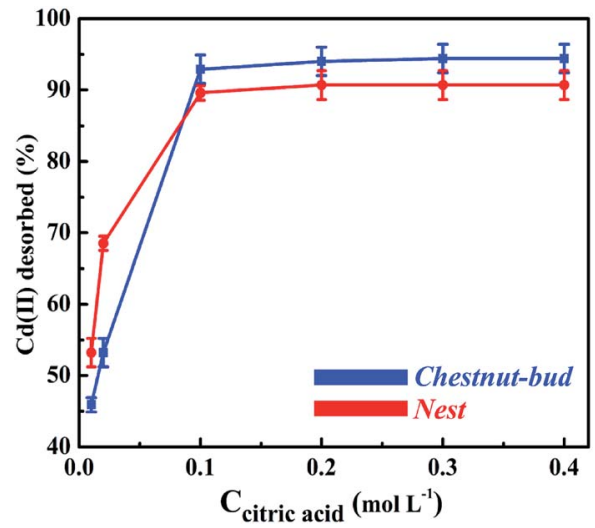

Fig. 22 Recovery of $\mathrm{Cd}(॥)$ desorbed from the chestnut buds and nests as a function of the citric acid concentration.

mild conditions without damaging the adsorbent itself. ${ }^{50}$ For the as-synthesized nanostructured $\alpha-\mathrm{Fe}_{2} \mathrm{O}_{3}$ adsorbents, the elution of $\mathrm{Cd}(\mathrm{II})$ was performed with citric acid as the eluent. The desorption percentages for $\mathrm{Cd}(\mathrm{II})$ adsorbed on the chestnut buds and nests as a function of the citric acid concentration are illustrated in Fig. 22. Approximately 45.9, 53.2, 92.9, 94, 94.4 and $94.4 \%$ of $\mathrm{Cd}(\mathrm{II})$ adsorbed on chestnut buds was eluted when the citric acid concentration was 0.01 , $0.02,0.1,0.2,0.3$ and $0.4 \mathrm{~mol} \mathrm{~L}^{-1}$, respectively. It is apparent that $0.2 \mathrm{~mol} \mathrm{~L}^{-1}$ citric acid gives the best desorption result. The same tendency was displayed for the nests, which indicates that the best desorption result can be achieved with $0.2 \mathrm{~mol} \mathrm{~L}^{-1}$ citric acid as the eluent.

Fig. 23 shows the results for the recovery of Cd(II) desorbed from the chestnut buds and nests as a function of the citric acid concentration. The adsorption capacities of the chestnut buds (Fig. 23A) and nests (Fig. 23B) did not decrease remarkably and remained at 160.0 and $115.2 \mathrm{mg} \mathrm{g}^{-1}$, respectively, after three repeated adsorption-desorption cycles using the same adsorbents. It could be concluded that the $\alpha-\mathrm{Fe}_{2} \mathrm{O}_{3}$ nanoparticles exhibit good regeneration ability, which would decrease the operational cost and expand the range of their sustainable application.

The FT-IR spectra of the $\alpha-\mathrm{Fe}_{2} \mathrm{O}_{3}$ chestnut buds and nests after three repeated adsorption-desorption cycles were examined to estimate the retention of their surface characteristics. As 

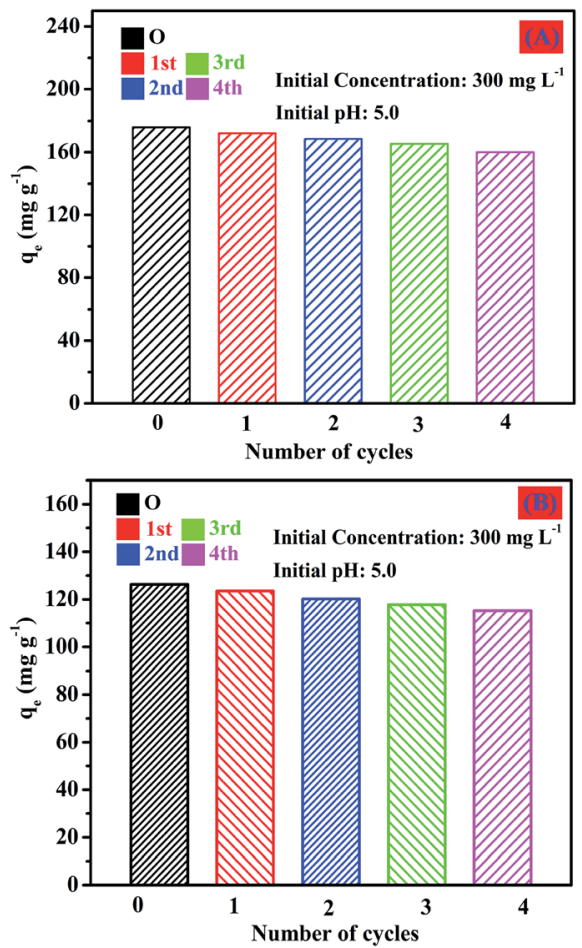

Fig. 23 Reusability of the chestnut buds and nests for adsorption of $\mathrm{Cd}(॥)$ with $0.2 \mathrm{~mol} \mathrm{~L}^{-1}$ citric acid as the eluent.

demonstrated in Fig. 24, the shapes of the peaks in the FT-IR spectra are almost the same as those shown in Fig. 6. It is clearly seen that the corresponding characteristic absorption peaks of $\mathrm{O}-\mathrm{H}$ stretching vibrations of the surface $\mathrm{OH}$ groups $\left(3400 \mathrm{~cm}^{-1}\right), \mathrm{Fe}-\mathrm{O}$ stretching vibrations (480 and $570 \mathrm{~cm}^{-1}$ ) and $\mathrm{Fe}-\mathrm{OH}$ bending vibrations $\left(1630 \mathrm{~cm}^{-1}\right)$ are still present upon repeated recycling. The above results indicate that the surface structure was not damaged during repeated processes of elution with citric acid. Therefore, both adsorbents, namely, chestnut buds and nests, possess excellent potential for sustainable application.

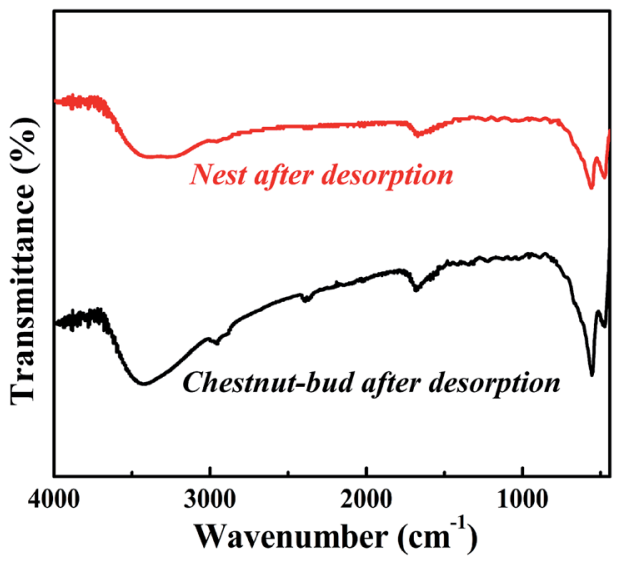

Fig. 24 FT-IR spectra of chestnut buds and nests after desorption.

\section{Conclusions}

We have successfully synthesized two kinds of nanostructured $\alpha-\mathrm{Fe}_{2} \mathrm{O}_{3}$ hierarchical hollow spheres, namely, chestnut buds and nests, by a facile solvothermal quasi-reverse-emulsiontemplated solvothermal process. Both $\alpha-\mathrm{Fe}_{2} \mathrm{O}_{3}$ nanoparticles exhibited highly porous characteristics with specific surface areas of 424.3 and $169.9 \mathrm{~m}^{2} \mathrm{~g}^{-1}$, respectively. The $\mathrm{pH}$ value of the Cd(II) solution and the initial Cd(II) concentration played significant roles in the adsorption capacity for $\mathrm{Cd}(\mathrm{II})$. The adsorption kinetics of Cd(II) showed that the uptake of Cd(II) by both adsorbents was fairly rapid and was in good agreement with the pseudo-second-order model. The adsorption isotherms were well described using the Langmuir isotherm, and the maximum monolayer adsorption capacities for $\mathrm{Cd}(\mathrm{II})$ of the chestnut buds and nests were 184.8 and $131.9 \mathrm{mg} \mathrm{g}^{-1}$, respectively. Furthermore, the adsorption capacities of the chestnut buds and nests did not decrease markedly and remained at 160.0 and $115.2 \mathrm{mg} \mathrm{g}^{-1}$, respectively, after three repeated adsorption-desorption cycles using the same adsorbents. Therefore, the hierarchical $\alpha-\mathrm{Fe}_{2} \mathrm{O}_{3}$ nanoparticles possess promising potential for the treatment of $\mathrm{Cd}(\mathrm{II})$ in contaminated water in engineering practice.

\section{Acknowledgements}

This work was supported by the Henan Key Scientific Research Project (16A430026 and 17A150048) and the Nanhu Scholars Program for Young Scholars of XYNU.

\section{Notes and references}

1 M. M. Khin, A. S. Nair, V. J. Babu, R. Murugan and S. Ramakrishna, Energy Environ. Sci., 2012, 5, 8075-8109.

2 I. Ali, Chem. Rev., 2012, 112, 5073-5091.

3 L. Gao, J. Chen, C. Tang, Z. Ke, J. Wang, Y. Shimizu and A. Zhu, Environ. Sci.: Processes Impacts, 2015, 17, 1769-1782.

4 Y. Hu and H. Cheng, Environ. Sci. Technol., 2013, 47, 37523760 .

5 M. H. Sun, S. Z. Huang, L. H. Chen, Y. Li, X. Y. Yang, Z. Y. Yuan and B. L. Su, Chem. Soc. Rev., 2016, 45, 3479-3563.

6 J. Lee, S. Mahendra and P. J. J. Alvarez, ACS Nano, 2010, 4, 3580-3590.

7 M. Khajeh, S. Laurent and K. Dastafkan, Chem. Rev., 2013, 113, 7728-7768.

8 P. Z. Ray and H. J. Shipley, RSC Adv., 2015, 5, 29885-29907. 9 S. Huang, L. Gu, N. Zhu, K. Feng, H. Yuan, Z. Lou and A. Shan, Green Chem., 2014, 16, 2696-2705.

10 S. Venkateswarlu and M. Yoon, Dalton Trans., 2015, 44, 18427-18437.

11 J. Su, Y. Zhang, S. Xu, S. Wang, H. Ding, S. Pan and H. Zhao, Nanoscale, 2014, 6, 5181-5192.

12 J. Chen, F. He, H. Zhang, X. Zhang, G. Zhang and G. Yuan, Ind. Eng. Chem. Res., 2014, 53, 18481-18488.

13 R. Zha, R. Nadimicherla and X. Guo, J. Mater. Chem. A, 2014, 2, 13932-13941. 
14 J. Qi, X. Lai, J. Wang, H. Tang, H. Ren, Y. Yang and Z. Su, Chem. Soc. Rev., 2015, 44, 6749-6773.

15 R. Purbia and S. Paria, Nanoscale, 2015, 7, 19789-19873.

16 G. Tian, Y. Chen, W. Zhou, K. Pan, Y. Dong, C. Tian and H. Fu, J. Mater. Chem., 2011, 21, 887-892.

17 J. H. Pan, X. Zhang, A. J. Du, D. D. Sun and J. O. Leckie, J. Am. Chem. Soc., 2008, 130, 11256-11257.

18 Z. Wei, R. Xing, X. Zhang, S. Liu, H. Yu and P. Li, ACS Appl. Mater. Interfaces, 2012, 5, 598-604.

19 B. Wang, H. B. Wu, L. Yu, R. Xu, T. T. Lim and X. W. Lou, Adv. Mater., 2012, 24, 1111-1116.

20 L. S. Zhong, J. S. Hu, H. P. Liang, A. M. Cao, W. G. Song and L. J. Wan, Adv. Mater., 2006, 18, 2426-2431.

21 T. J. Park and S. S. Wong, Chem. Mater., 2006, 18, 5289-5295.

22 K. Simeonidis, S. Mourdikoudis, E. Kaprara, M. Mitrakas and L. Polavarapu, Environ. Sci.: Water Res. Technol., 2016, 2, 43-70.

23 Z. Liu, R. Yu, Y. Dong, W. Li and W. Zhou, RSC Adv., 2016, 6, 82854-82861.

24 E. M. Verdugo, Y. Xie, J. Baltrusaitis and D. M. Cwiertny, RSC $A d v .$, 2016, 6, 99997-100007.

25 X. Hu, J. C. Yu, J. Gong, Q. Li and G. Li, Adv. Mater., 2007, 19, 2324-2329.

26 J. Hu, M. Chen, X. Fang and L. Wu, Chem. Soc. Rev., 2011, 40, 5472-5491.

27 R. Sui and P. Charpentier, Chem. Rev., 2012, 112, 3057-3082.

28 R. Yuan, X. Fu, X. Wang, P. Liu, L. Wu, Y. Xu and Z. Wang, Chem. Mater., 2006, 18, 4700-4705.

29 J. H. Bang and K. S. Suslick, J. Am. Chem. Soc., 2007, 129, 2242-2243.

30 M. Chen, W. Li, X. Shen and G. Diao, ACS Appl. Mater. Interfaces, 2014, 6, 4514-4523.

31 S. W. Cao and Y. J. Zhu, J. Phys. Chem. C, 2008, 112, 62536257.

32 H. G. Yang and H. C. Zeng, Angew. Chem., Int. Ed., 2004, 43, 5206-5209.

33 Z. Ding, G. Q. Lu and P. F. Greenfield, J. Phys. Chem. B, 2000, 104, 4815-4820.
34 Y. B. Luan, L. Q. Jing, M. Z. Xie, X. Shi, X. X. Fan, Y. Cao and Y. J. Feng, Phys. Chem. Chem. Phys., 2012, 14, 1352-1359.

35 H. Li, Q. Zhao, X. Li, Y. Shi and G. Chen, Appl. Surf. Sci., 2012, 258, 7099-7104.

36 S. Li, H. Zhang, J. Wu, X. Ma and D. Yang, Cryst. Growth Des., 2006, 6, 351-353.

37 L. S. Zhong, J. S. Hu, H. P. Liang, A. M. Cao, W. G. Song and L. J. Wan, Adv. Mater., 2006, 18, 2426-2431.

38 H. Li, Q. Zhao, X. Li, Y. Shi and G. Chen, Appl. Surf. Sci., 2012, 258, 7099-7104.

39 T. Abe, Y. Kashiwaba, M. Baba, J. Imai and H. Sasaki, Appl. Surf. Sci., 2001, 175, 549-554.

40 D. Chen, W. Shen, S. Wu, C. Chen, X. Luo and L. Guo, Nanoscale, 2016, 8, 7172-7179.

41 Y. Pan, Z. Liu, W. Wang, C. Peng, K. Shi and X. Ji, J. Mater. Chem. A, 2016, 4, 2537-2549.

42 V. Venkateswaran, P. Kalaamani and N. Karpagam, Chem. Sci. Trans., 2015, 4, 347-354.

43 J. C. Soares, A. C. Soares, P. A. R. Pereira, V. da Cruz Rodrigues, F. M. Shimizu, M. E. Melendez and O. N. Oliveira, Phys. Chem. Chem. Phys., 2016, 18, 8412-8418.

44 Y. Wang, X. W. Tang, Y. M. Chen, L. T. Zhan, Z. Z. Li and Q. Tang, J. Hazard. Mater., 2009, 172, 30-37.

45 Y. H. Li, J. Ding, Z. K. Luan, Z. C. Di, Y. F. Zhu, C. L. Xu, D. H. Wu and B. Q. Wei, Carbon, 2003, 41, 2787-2792.

46 T. S. Anirudhan, N. B. Fernandez and M. D. Mullassery, J. Chem. Technol. Biotechnol., 2012, 87, 714-722.

47 S. Venkateswarlu and M. Yoon, $R S C A d v ., 2015,5$, 6544465453.

48 L. Liu, L. Q. Yang, H. W. Liang, H. P. Cong, J. Jiang and S. H. Yu, ACS Nano, 2013, 7, 1368-1378.

49 Y. Wang, G. Ye, H. Chen, X. Hu, N. Zheng and S. Ma, J. Mater. Chem. A, 2015, 3, 15292.

50 L. D. Bitonto, A. Volpe, M. Pagano, G. Bagnuolo, G. Mascolo, V. L. Parola and C. Pastore, J. Hazard. Mater., 2017, 324, 168177. 